\title{
Digital Mental Health Interventions for Depression, Anxiety, and Enhancement of Psychological Well-Being Among College Students: Systematic Review
}

Emily G Lattie ${ }^{1}, \mathrm{PhD}$; Elizabeth C Adkins ${ }^{1}$, MA; Nathan Winquist ${ }^{1}, \mathrm{BA}$; Colleen Stiles-Shields ${ }^{2}, \mathrm{PhD}$; Q Eileen Wafford $^{3}$, MST, MLiS; Andrea K Graham ${ }^{1}$, PhD

\footnotetext{
${ }^{1}$ Center for Behavioral Intervention Technologies, Northwestern University, Chicago, IL, United States

${ }^{2}$ Department of Psychiatry and Behavioral Sciences, Rush University Medical Center, Chicago, IL, United States

${ }^{3}$ Galter Health Sciences Library and Learning Center, Northwestern University, Chicago, IL, United States
}

\section{Corresponding Author:}

Emily G Lattie, PhD

Center for Behavioral Intervention Technologies

Northwestern University

750 N Lake Shore Drive

10th Floor

Chicago, IL, 60611

United States

Phone: 13125033741

Email: emily.lattie@northwestern.edu

\section{Abstract}

Background: College students are increasingly reporting common mental health problems, such as depression and anxiety, and they frequently encounter barriers to seeking traditional mental health treatments. Digital mental health interventions, such as those delivered via the Web and apps, offer the potential to improve access to mental health treatment.

Objective: This study aimed to review the literature on digital mental health interventions focused on depression, anxiety, and enhancement of psychological well-being among samples of college students to identify the effectiveness, usability, acceptability, uptake, and adoption of such programs.

Methods: We conducted a systematic review using the Preferred Reporting Items for Systematic Reviews and Meta-Analyses guidelines (registration number CRD42018092800), and the search strategy was conducted by a medical research librarian in the following databases: MEDLINE (Ovid), EMBASE (Elsevier), PsycINFO (EbscoHost), the Cochrane Library (Wiley), and Web of Science (Thomson Reuters) from the date of inception to April 2019. Data were synthesized using a systematic narrative synthesis framework, and formal quality assessments were conducted to address the risk of bias.

Results: A total of 89 studies met the inclusion criteria. The majority of interventions $(71 / 89,80 \%)$ were delivered via a website, and the most common intervention was internet-based cognitive behavioral therapy $(28,31 \%)$. Many programs $(33,37 \%)$ featured human support in the form of coaching. The majority of programs were either effective $(42,47 \%)$ or partially effective (30, 34\%) in producing beneficial changes in the main psychological outcome variables. Approximately half of the studies $(45,51 \%)$ did not present any usability or acceptability outcomes, and few studies $(4,4 \%)$ examined a broad implementation of digital mental health interventions on college campuses. Quality assessments revealed a moderate-to-severe risk of bias in many of the studies.

Conclusions: Results suggest that digital mental health interventions can be effective for improving depression, anxiety, and psychological well-being among college students, but more rigorous studies are needed to ascertain the effective elements of these interventions. Continued research on improving the user experience of, and thus user engagement with, these programs appears vital for the sustainable implementation of digital mental health interventions on college campuses.

(J Med Internet Res 2019;21(7):e12869) doi: $\underline{10.2196 / 12869}$

\section{KEYWORDS}

eHealth; mHealth; mental health; students; universities 


\section{Introduction}

In the last decade, rising rates of college students experiencing symptoms of depression and anxiety have been observed [1-3]. Globally, approximately $31 \%$ of college students screened positive for a mental health disorder over the course of the last year [4]. It has also been increasingly recognized that accessing treatment for these common mental health problems is difficult. Many students have low mental health literacy and do not recognize a need for treatment but rather believe that these depression and anxiety symptoms are typical college stress and, therefore, do not warrant treatment [5]. Students who do recognize a need for mental health services often face multiple barriers to accessing care, perceive the care available to them as inconvenient, and are skeptical about the efficacy of care $[6,7]$.

Campus counseling centers are well positioned to provide mental health care. However, many counseling centers across the country are underresourced, have difficulty reaching students in need, and operate at full capacity during much of the year [8].

Digital mental health interventions, such as those delivered via mobile- and Web-based platforms, offer the possibility of treatment to college students with common mental health problems while circumventing many existing barriers to receiving traditional mental health services, including stigma and time [9-11].

The evidence base for digital mental health interventions for general adult populations is vast [12-15], and the evidence base for college and university student populations is rapidly accumulating. In 2013, a systematic review of technology-based interventions for mental health in tertiary students found that these types of interventions offer promise for improving symptoms of certain mental health problems, but it concluded that more research was needed [16]. A 2014 systematic review and meta-analysis of computer-delivered and Web-based interventions for university students found that these types of interventions can be effective in improving depression, anxiety, and stress among students [17]. More recently, a 2018 systematic review and meta-analysis found that internet interventions can have small-to-moderate effects on a range of mental health conditions [18].

However, there have been limitations of these past reviews, as they have focused exclusively on studies that were randomized controlled trials (RCTs). Although a focus on studies with RCT designs allows researchers to evaluate the efficacy and effectiveness of digital mental health interventions, the exclusion of papers reporting on other study designs presents a significant gap in our ability to assess the uptake and adoption of digital mental health interventions for university students (which could be assessed in nonrandomized designs, including single-arm trials in which an intervention is made available to all students on campus). This is particularly important as the full public health potential of these types of interventions is tied not only to clinical efficacy but also to the successful implementation of these programs in real-world settings. Across the board, the implementation and integration of digital health tools into routine care settings has been a challenge. Many have called for testing digital health tools under more pragmatic conditions to maximize the transfer of knowledge from research trials to real-world implementation [19-21], and studies examining the real-world uptake and engagement with digital mental health tools have generally found low engagement and completion rates [22]. Furthermore, in recent years, increased focus has been on assessing the user experience (including the usability and acceptability) of such interventions to identify and rectify user experience failings that could limit one's ability and desire to continue to use a program [23-25]. The aim of this systematic review was to evaluate the effectiveness, usability, acceptability, uptake, and adoption of digital mental health interventions for treating depression and anxiety and for enhancing psychological well-being among college students. Characteristics of the student digital mental health interventions have been described here.

\section{Methods}

\section{Eligibility Criteria}

To be included in this review, studies had to (1) examine an intervention that aimed to improve psychological well-being, psychological distress, stress, depressive, and/or anxious symptoms; (2) deliver the intervention via a digital platform (including mobile phone, website, virtual reality systems, and offline computer programs; they could be delivered as an adjunct to face-to-face interventions); (3) include students enrolled in higher education institutions, such as 2-year community colleges, professional schools (eg, medical school and nursing school), 4-year colleges (ie, bachelor's degree-granting institutions that do not offer graduate degrees), and universities; (4) report outcomes related to psychological well-being, psychological distress, stress, depressive and anxious symptoms, and/or the use and reach of an intervention; and (5) be written in English. In this paper, we use the term college students to refer to all students in postsecondary education, including medical students. All study designs were included, with the exception of technical validation papers reporting exclusively on the development of digital mental health interventions. Conference abstracts were also excluded.

\section{Search Strategy}

A comprehensive search strategy was developed using keywords and controlled vocabulary to describe university students, depression and anxiety, and digital mental health interventions. The search strategy was adapted to the electronic databases MEDLINE (Ovid), EMBASE (Elsevier), PsycINFO (EBSCOhost), Web of Science (Thomson Reuters), and the Cochrane Library (Wiley). Each database was searched from the date of inception to April 18, 2019. As some relevant journals (ie, JMIR Mental Health and Digital Health) are not indexed in the searched sources, an additional handsearch was conducted through these publications and through the reference lists of related systematic reviews. The searches were not limited based on publication date, language, document type, or study design. Throughout the study selection, the reference lists of included studies were further reviewed to identify relevant citations. The search strategy terms are presented in Multimedia Appendix 1. The review adhered to the Preferred Reporting 
Items for Systematic Reviews and Meta-Analyses (PRISMA) guidelines [26] and was registered before data extraction on the international prospective register of systematic reviews PROSPERO website (registration number CRD42018092800).

\section{Study Selection}

Search results were uploaded into Rayyan, a Web-based software program that allows for reviewers to collaborate during the study selection process [27]. Two reviewers independently screened each of the titles and abstracts from the initial literature search against the inclusion criteria. Authors EGL, ECA, NW, CSS, and AKG served as reviewers. Full-text articles for the approved articles were then screened independently by 2 reviewers. Discrepancies about inclusion were resolved by discussion, and a third reviewer was brought into the discussion if necessary.

\section{Data Extraction}

Two reviewers extracted the data independently from each eligible study using a Web-based extraction form that was piloted and calibrated with all reviewers before formal data extraction. Discrepancies about data extraction were resolved by discussion, and a third reviewer was brought into the discussion if necessary. The data extracted included the study location, study design, type of comparator, type of prevention/treatment, type of technology, name of technology/program, type of program, primary intervention target(s), presence of support, student population, setting, sample size, length of intervention, usability and acceptability outcomes, uptake and adoption outcomes, psychological outcomes, and type of analyses performed (ie, completer or intent to treat).

\section{Outcomes}

This review examined the effectiveness, usability, acceptability, uptake, and adoption of digital mental health interventions for treating depression and anxiety and for enhancing psychological well-being among college students. The effectiveness outcomes included measures of depressive symptomatology (eg, Beck Depression Inventory-II [28] and Patient Health Questionnaire [29]), measures of anxious symptomatology (eg, Beck Anxiety Inventory [30] and Anxiety Sensitivity Inventory [31]), and measures of psychological distress and well-being (eg, Perceived Stress Scale [32] and Scales of Psychological Well-being [33]).

For the purpose of this review, usability was defined as the quality of a user's experience when interacting with a program. Usability is an umbrella term that includes the ease of learning a program, the efficiency of use, the memorability of it, and the subjective satisfaction with a program. The usability outcomes include standard usability measures (eg, the System Usability Scale [34]) and qualitative usability reports. Acceptability is specifically about satisfaction with different aspects of the program and was primarily measured through qualitative self-reporting.

For the purpose of this review, the terms uptake and adoption were used in conjunction with one another [35] and were together defined as the action of trying an innovation. Thus, uptake and adoption outcomes were primarily metrics on the number of downloads and uses and were intended to be described alongside the number of users relative to the population of potential users when available (to determine the rates of service penetration [35]). However, few studies provided these details. Metrics on the completion of follow-up assessments and study attrition (or fidelity to the intervention) were examined in studies that did not provide detailed program usage metrics to allow for further implementation-related insights to be gathered.

\section{Quality Assessment}

As this review included both randomized trials and nonrandomized trials, the risk of bias was assessed using 2 separate tools: the Cochrane Collaboration's tool for assessing risk of bias in randomized trials [36] and the Cochrane Collaboration's tool for assessing risk in nonrandomized studies of interventions [37]. For randomized trials, risk of bias was evaluated for selection bias, performance bias, detection bias, attrition bias, and reporting bias using the anchors of a low, high, or unclear risk of bias. For nonrandomized trials, risk of bias was evaluated for bias because of confounding, bias in selection of participants into the study, bias in classification of interventions, bias because of deviations from intended interventions, bias because of missing data, bias in measurement of outcomes, and bias in selection of the reported result.

\section{Data Synthesis}

A systematic narrative framework was used to synthesize the data [38-40]. Owing to the high degree of heterogeneity in outcomes and measurement included in this study, a meta-analytic approach was not appropriate. Following the systematic narrative framework for literature reviews [39], the results of included studies were synthesized and presented without reference to the statistical significance of the findings.

\section{Results}

\section{Included Studies}

A total of 6428 article titles and abstracts were reviewed. Then, 187 full-text articles were reviewed for inclusion, with 89 studies included in the review for data extraction. See Figure 1 for the PRISMA flow diagram. 
Figure 1. Preferred Reporting Items for Systematic Reviews and Meta-Analyses flow diagram.

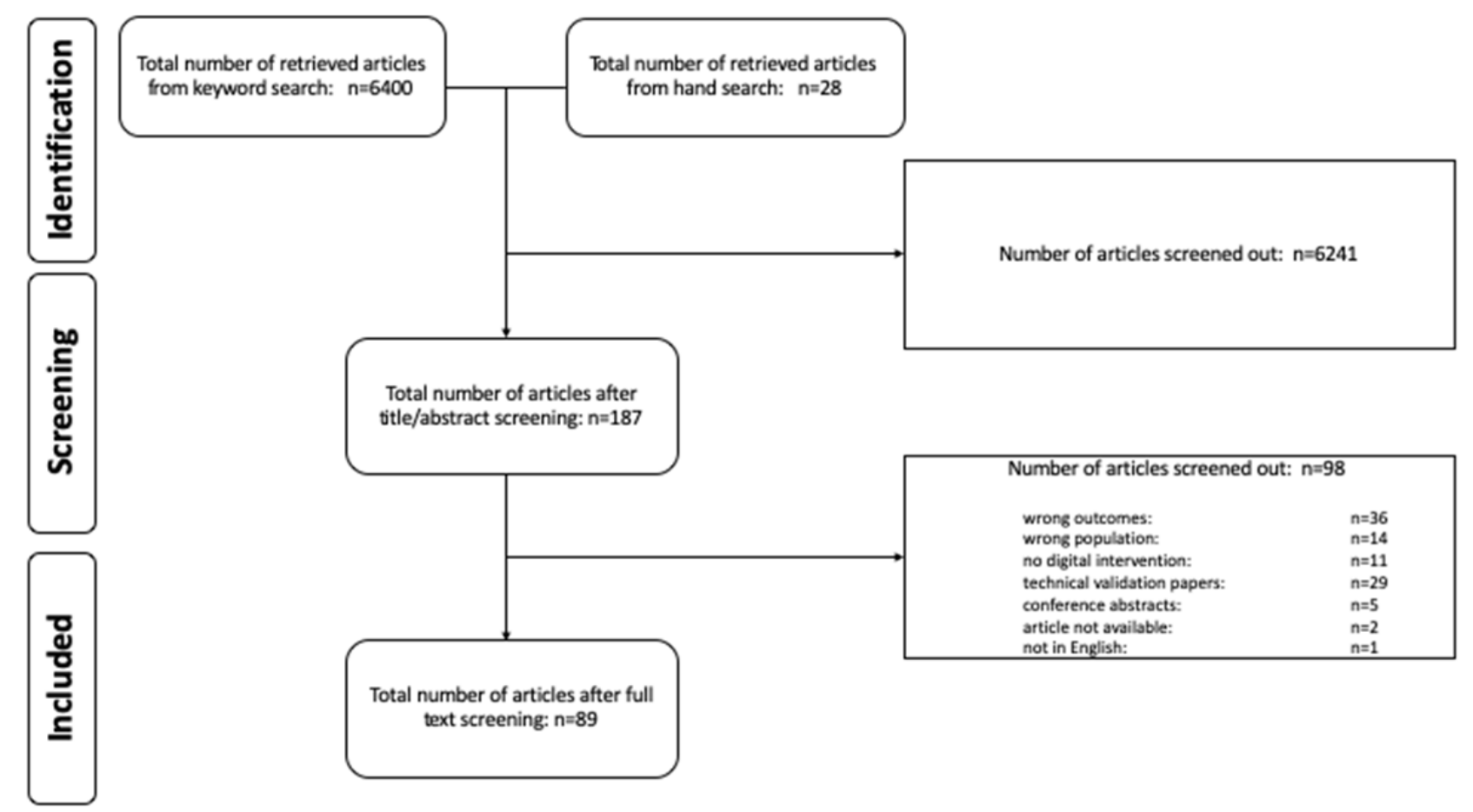

\section{Study Characteristics}

Of the 89 studies included in this review, 72 employed randomized study designs [41-112], whereas the remaining 17 were nonrandomized [113-129]. One of the included studies [83] was a secondary analysis of another included study [84]. Another one of the included studies [129] was a qualitative study of the usability and acceptability of another included study [101]. The vast majority of the included studies $(n=81$ [41-44,47-52,54-56,58-111,113,114,116-120,122,123,125-129]) took place at universities, with far fewer taking place at 4-year colleges $(n=2[45,46])$, at health professional schools (eg, medical school and nursing school; $n=5[57,115,121,124,130])$, and at community colleges $(n=1$ [53]). Approximately half of the studies $(n=44[42-48,50,53,55,56,58-61,63,65,66,72,73$, 76-78,81,87-90,93,95,98,99,101-104,106,108,110,116-118, 122,125]) targeted undergraduate students exclusively. Most studies included were focused on either universal prevention programs $\quad(n=36 \quad[43,48,53,54,63-67,70-73,75-78,90,91$, 94,95,97,99,100,102,106-108,110-112,114,118,119,125,126]), or on treatment intervention programs $(n=22[41,49,50,52$, $58,69,74,79,80,83-86,88,89,92,98,113,117,120,122,127])$.

We examined if each study appeared to be designed specifically for students (eg, the purpose of the study was focused on college student mental health) or if college students appeared to be used as a convenience sample. As seen in Multimedia Appendix 2, a minority of the studies $(n=12 \quad[44,71,89,90,93,95,104$, $110,111,114,118,123])$ appeared to use college students as a convenience sample, and for an additional 9 studies, it was unclear if the program was being tested specifically for college student mental health or if college students were a convenience sample $[47,50,51,61,64,68,84,105,122]$.

The majority of these studies $(n=46$ [43-48,51-55,57-59, $62,65-67,69,72,76-78,86,87,113,116,119,120,122,124-127,131])$ took place in the United States. As seen in Multimedia Appendix 2, several studies also took place in the United Kingdom $(n=6$ $[60,73,75,80,96,114])$, Ireland $(n=5[83-85,117,123])$, Australia $(\mathrm{n}=5[50,61,74,109,115])$, Canada $(\mathrm{n}=5[42,49,81,102,103])$, and China (n=5 [70,71,89,91,100]).

A total of 71 studies utilized a Web-based technology ([42-44, 46,49,50,53-55,57,59-88,90,91,94,96-101,103-110,112,113,115-121, 123-126,128]), and 8 studies utilized interventions delivered via mobile phone (app-based programs and short message service-based programs) [52,56,59,95,101,102,114,129]. Furthermore, 11 studies utilized offline computer-based programs [41,45,47,51,52,89,92,93,105,111,127], and 3 studies focused on virtual reality programs $[58,111,122]$. As seen in Multimedia Appendix 2, some studies included more than one type of technology, and thus, the numbers reported in the previous sentence add up to more than the 89 studies included in this review. Although the interventions examined were variable in content and in length, the most common type of intervention examined was internet-based cognitive behavioral therapy $(n=28[42,49,50,57,61,68,72-75,79-81,83-86,88,98,101$, $103,107,109,112,113,123,128,129])$. The modal length of intervention was 8 weeks. Most studies focused on digital mental health programs developed for the specific study, whereas a minority of studies $(n=15)$ focused on publicly available interventions (ie, Beating the Blues, $\mathrm{n}=3[83,84,86]$; MoodGYM, $\mathrm{n}=5$ ([50,57,68,98,112]); Therapist-Assisted Online, $\mathrm{n}=1$ [113]; Headspace and Smiling Mind, $n=1$ [95]; Family eJournal, $n=1$ [90]; Tess chatbot, $n=1$ [97]; DeStressify, $n=1$ [102]; Overcome Social Anxiety, n=1 [103]); SilverCloud Health's Space from Depression, Space from Anxiety, and Space from Stress, $n=1$ [128]; and CareCollaborateConnect: Student Success and thedesk, $\mathrm{n}=1$ [109]). 
The majority of interventions studied offered some level of support or guidance to users-many of these interventions featured coaching from a human $(n=33 \quad[41,49-51,58$ ,62-66,69,71,73,74,76,79,82-88,94,101,104,105,107,116,122,123,128,129]), whereas others featured automated support $(n=18[44,48$, $53,57,59,67,70,77,91,98-101,106,108,112,113,115])$, such as prescripted emails. Several studies examined self-guided interventions $(\mathrm{n}=33[42,43,45,46,52,54-56,60,61,68,72,75,78$, $80,81,89,90,92,93,95,97,102,103,109-111,114,118,119,121,124,125])$ in which the participants only had contact with the study staff for research assessments; few studies focused on technology as an adjunct to therapy $(\mathrm{n}=5[47,86,100,120,126]), 2$ studies provided peer support [96,117], and 1 study had an unclear presence of support $(\mathrm{n}=1$ [127]).

\section{Effectiveness of Interventions Studied on Psychological Outcomes}

As seen in Multimedia Appendix 3, the majority of studies reported that the digital mental health intervention(s) of interest were either effective (eg, improvements were observed in all main outcomes; $\mathrm{n}=42[41,42,45,47-51,54,56,57,59,60,62,63$, $68,71,78,79,84-89,92,93,100,101,103,112,113,115,120,122,123,125$, $127,128,131])$ or partially effective (eg, improvements were observed in some main outcomes; $n=30[43,44,52,53,58,61$, $65,67,69,70,72-77,80-82,90,91,94-97,99,102,108,111,124])$ in producing beneficial changes in the main psychological outcome variables. A minority of studies reported on interventions that were not effective $(n=10[46,55,64,66,98,114,117])$ or did not report on psychological outcomes and focused on program usage or usability $(n=6[116,118,119,121,126,129])$. An examination of intervention effectiveness by type of technology used follows. Of the 71 studies that included a Web-based intervention, 30 were effective, 25 were partially effective, 8 were not effective at producing beneficial changes in the main psychological outcome variables, and for 8 studies, effectiveness was not applicable. Of the 8 studies that included interventions delivered via mobile phone, 3 were effective, 3 were partially effective, 1 was not effective, and for 1 study, effectiveness was not applicable. Of the 11 studies that included offline computer-based programs, 10 were effective and 1 was partially effective. Of the 3 studies that included a virtual reality-based intervention, 1 was effective and 2 were not effective.

Of the 42 studies deemed effective in producing beneficial changes in the main psychological outcome variables, 36 of those studies utilized a control condition; although the quality of control conditions varied broadly and ranged from treatment as usual or waitlists to other digital programs or face-to-face treatment $[41,42,45,47,48,50,51,54,56,57,59,60,71,78,79,84$, $86,88,89,92,93,100,101,103,105,107,109,112,113,125]$. See Multimedia Appendix 2 for more information. Some studies targeted general mental health and well-being and listed several primary outcome variables; thus, it was difficult to ascertain whether the intervention was fully effective. To provide a conservative estimate, these studies were counted as partially effective.

\section{Usability and Acceptability of Interventions Studied}

Approximately half of the studies included in this review $(n=45$ [41-44,48,54-57,59,60,62,63,70,73,76-78,81,84,85,87-93,96,
100,102,104,106,110,111-113,116,118,121-125,127]) did not present any usability or acceptability outcomes. In those studies that presented usability and acceptability outcomes, the results were generally favorable. However, response rates were often low (which was specifically noted in the studies by Lintvedt et al [68] and Mailey et al [69]), so it is difficult to ascertain the true acceptability of these interventions as those who continued to engage with the study procedures may have found the interventions more useful and usable than those who did not.

As seen in Multimedia Appendix 3, studies that presented usability and/or acceptability outcomes typically relied on single-item Likert scales, questionnaires, or user feedback interviews rather than validated measures. A minority of studies used validated measures such as the System Usability Scale $[65-67,120,132]$ to assess usability and the Client Satisfaction Questionnaire [61,71,86,133] to assess acceptability. The results of formal usability testing were not presented in any of the studies.

\section{Uptake and Adoption of Interventions Studied}

The vast majority of studies did not specify the size of the pool of potential participants from which the study participants were drawn $\quad(\mathrm{n}=81 \quad[41-54,56-61,63-71,73-91,93-101,103-105$, 107-111,113-115,117-127,129]) and recruited from seemingly large pools of students. Furthermore, many studies did not present the metrics on the usage of the digital mental health interventions $(n=29[44,45,48,50,53,56,69,70,73,74,76-78,81$, $89,90,93,98,99,103-105,107,109-111,113,114,124]$. As detailed program usage metrics were not addressed by the authors of several included studies, the Uptake and Adoption column in Multimedia Appendix 3 includes additional data on completion of follow-up assessments and study attrition as a proxy for intervention uptake and adoption. For studies that did not provide clear metrics on the completion of follow-up assessments and/or study attrition, we have listed not reported in this column. For studies that examined digital mental health interventions in standardized laboratory settings, we have listed N/A due to standardized within-lab use.

Relatively few studies examined the implementation of a digital mental health intervention on a college campus and reported on the implementation outcomes $[35,93,98]$. Although a small handful of studies reported on the broad uptake and adoption of programs that were implemented on college campuses $[86,116,119,128]$, the Beating the Blues implementation by Santucci et al [86] and the SilverCloud implementation by Palacios et al [128] were the only studies in which the feasibility of implementing a digital mental health program was explicitly discussed. Santucci et al set out to assess the feasibility, acceptability, and effectiveness of Beating the Blues for university students (as benchmarked to published trials) and outlined their process of conducting a needs assessment and engaging stakeholders before commencing the trial [86]. They found preliminary support for the feasibility of disseminating and implementing Beating the Blues in a university health center and effectiveness similar to what had been documented in a previous RCT. Palacios et al [128] conducted an open trial in which 3 SilverCloud programs-Space from Depression, Space from Anxiety, and Space from Stress-were made available to 
the students and were advertised through on-campus counseling centers. The majority of the participants found the programs helpful and found benefit in having a supported Web-based intervention available on campus, and the programs demonstrated feasibility, acceptability, and effectiveness.

As seen in Multimedia Appendix 3, many studies had high rates of attrition and low rates of sustained program use. Although usage was variable and cannot be directly compared across studies, a pattern emerged such that for module-based interventions, usage dropped over an individual's time spent in the study. For example, module 1 program completion rates were generally high, and in many studies examined, a minority of participants completed all available modules.

\section{Risk of Bias}

As seen in Table 1, of the 72 randomized studies, 28 studies were judged as having a low risk of bias ([41,44,47,54,57, $60,64,66,75,78,84,86,88,91,92,94,95,97,99,100,101,102-104$, 109,111,112]) and only 9 studies were judged as having a high risk of bias $[45,49,58,63,65,72,83,96,110]$. The remaining 35 studies were judged as having some concerns regarding bias $[42,43,46,48,50-53,55,56,59,61,62,67-71,73,74,76,77,79-82,85,87,89,90$, 93,98,105-108,131]. Risk of bias most frequently emerged because of a potential bias in measurement of the outcome. Some concerns were noted in this domain for roughly one-third of the studies $(n=27[42,46,49,50,52,53,55,56,58,59,61-63$, $65,67-70,72-74,76,81,82,85,87,89])$ because outcomes were self-reported in nature and the participants were aware of the intervention they received. Concerns were often noted regarding potential bias arising from the randomization process, and potential bias because of missing outcome data that were not analyzed in a manner to minimize risk [80-82]. Potential bias arising from the randomization process was frequently noted because of baseline imbalances that suggested problems with randomization. Concerns surrounding risk of bias because of missing outcome data were frequently related to high levels of attrition, which is a particularly common problem in studies of digital mental health interventions.

Of the 16 nonrandomized studies screened for risk of bias, the majority of studies ( $n=10 \quad[113-115,117,120,122-125,128])$ demonstrated a serious risk of bias using the Risk of Bias in Non-Randomized Studies of Interventions (ROBINS-I) rating scale, and 1 study demonstrated a critical risk of bias [127]. One qualitative study [129] from which we extracted usability and acceptability data was not included in the risk-of-bias assessments. This study collected data from participants of an already analyzed RCT [101]. The details are provided in Table 2. Risk of bias is more common in nonrandomized studies, and the 3 studies that were determined to have a low risk of bias $[116,118,119]$ all reported on the uptake and adoption of digital mental health programs as their main outcomes. As these metrics were objective, minimal risk of bias was identified. For the majority of studies, a potential for bias was identified in the measurement of outcomes, as outcomes were self-reported in nature and the participants were aware of the intervention they received. 
Table 1. Risk of bias for randomized studies.

\begin{tabular}{|c|c|c|c|c|c|c|}
\hline Authors and year of publication & $\mathrm{Dmn}^{\mathrm{a}} \# 1^{\mathrm{b}}$ & Dmn $\# 2^{\mathrm{c}}$ & Dmn \#3 ${ }^{\mathrm{d}}$ & Dmn \#4 ${ }^{\mathrm{e}}$ & Dmn $\# 5^{\mathrm{f}}$ & Overall risk \\
\hline Alvarez et al, 2008 [41] & $\mathrm{LR}^{\mathrm{g}}$ & LR & LR & LR & LR & LR \\
\hline Arpin-Cribbie et al, 2012 [42] & LR & LR & LR & $\mathrm{SC}^{\mathrm{h}}$ & LR & $\mathrm{SC}$ \\
\hline Asbury et al, 2018 [90] & $\mathrm{SC}$ & $\mathrm{SC}$ & LR & LR & LR & $\mathrm{SC}$ \\
\hline Auyeung \& Mo, 2018 [91] & LR & LR & LR & LR & LR & LR \\
\hline Bedford et al, 2018 [92] & LR & LR & LR & LR & LR & LR \\
\hline Booker \& Dunsmore, 2017 [43] & $\mathrm{LR}$ & $\mathrm{SC}$ & $\mathrm{SC}$ & LR & $\mathrm{LR}$ & $\mathrm{SC}$ \\
\hline Braithwaite \& Fincham, 2009 [44] & LR & LR & LR & LR & LR & LR \\
\hline Braithwaite \& Fincham, 2007 [93] & $\mathrm{SC}$ & LR & $\mathrm{SC}$ & LR & LR & $\mathrm{SC}$ \\
\hline Buglione et al, 1990 [45] & $\mathrm{SC}$ & $\mathrm{SC}$ & $\mathrm{SC}$ & LR & LR & $\mathrm{HR}^{\mathrm{i}}$ \\
\hline Chiauzzi et al, 2008 [46] & LR & LR & LR & $\mathrm{SC}$ & LR & $\mathrm{SC}$ \\
\hline Cohen et al, 1999 [47] & LR & LR & LR & LR & LR & LR \\
\hline Cukrowicz \& Joiner, 2007 [48] & $\mathrm{SC}$ & LR & LR & LR & LR & $\mathrm{SC}$ \\
\hline Day et al, 2013 [49] & LR & LR & HR & $\mathrm{SC}$ & LR & HR \\
\hline Ellis et al, 2011 [50] & LR & LR & LR & $\mathrm{SC}$ & LR & LR \\
\hline Eustis et al, 2018 [94] & LR & LR & $\mathrm{LR}$ & LR & LR & LR \\
\hline Fernandez et al, 1986 [51] & LR & LR & LR & LR & $\mathrm{SC}$ & $\mathrm{SC}$ \\
\hline Fitzpatrick et al, 2017 [52] & LR & LR & LR & $\mathrm{SC}$ & LR & $\mathrm{SC}$ \\
\hline Flett et al, 2019 [95] & LR & LR & LR & LR & LR & LR \\
\hline Frazier et al, 2015 [53] & LR & LR & LR & $\mathrm{SC}$ & LR & $\mathrm{SC}$ \\
\hline Freeman et al, 2008 [96] & $\mathrm{SC}$ & LR & HR & HR & LR & HR \\
\hline Frith \& Loprinzi, 2017 [54] & LR & LR & LR & LR & LR & LR \\
\hline Fulmer et al, 2018 [97] & LR & LR & LR & LR & LR & LR \\
\hline Geisner et al, 2015 [55] & LR & LR & LR & $\mathrm{SC}$ & LR & $\mathrm{LR}$ \\
\hline Gibbel, 2010 [98] & LR & $\mathrm{SC}$ & LR & LR & LR & $\mathrm{SC}$ \\
\hline Grassi et al, 2011 [56] & LR & LR & $\mathrm{SC}$ & $\mathrm{SC}$ & LR & $\mathrm{SC}$ \\
\hline Greer, 2015 [99] & LR & LR & LR & LR & $\mathrm{LR}$ & LR \\
\hline Guille et al, 2015 [57] & LR & LR & LR & LR & LR & LR \\
\hline Hall et al, 2018 [100] & LR & LR & $\mathrm{LR}$ & LR & LR & LR \\
\hline Harrer et al, 2018 [101] & LR & LR & LR & LR & LR & LR \\
\hline Harris et al, 2002 [58] & $\mathrm{HR}$ & LR & HR & $\mathrm{SC}$ & LR & $\mathrm{HR}$ \\
\hline Hintz et al, 2015 [59] & LR & LR & LR & $\mathrm{SC}$ & LR & $\mathrm{SC}$ \\
\hline Hoppitt et al, 2014 [60] & LR & LR & LR & LR & LR & $\mathrm{LR}$ \\
\hline Howell et al, 2018 [112] & LR & LR & LR & LR & LR & LR \\
\hline Kenardy et al, 2003 [61] & LR & LR & LR & $\mathrm{SC}$ & LR & $\mathrm{SC}$ \\
\hline King et al, 2015 [62] & LR & LR & LR & $\mathrm{SC}$ & LR & $\mathrm{SC}$ \\
\hline Koydemir \& Sun-Selisik, 2016 [63] & $\mathrm{SC}$ & $\mathrm{SC}$ & HR & $\mathrm{SC}$ & LR & HR \\
\hline Kvillemo et al, 2016 [64] & LR & LR & LR & LR & LR & LR \\
\hline Lee \& Jung, 2018 [102] & LR & LR & LR & LR & LR & LR \\
\hline Levin et al, 2014 [65] & LR & LR & LR & $\mathrm{SC}$ & HR & HR \\
\hline Levin et al, 2016 [66] & LR & LR & LR & LR & LR & LR \\
\hline Levin et al, 2017 [67] & LR & LR & LR & $\mathrm{SC}$ & LR & $\mathrm{SC}$ \\
\hline
\end{tabular}




\begin{tabular}{|c|c|c|c|c|c|c|}
\hline Authors and year of publication & $\mathrm{Dmn}^{\mathrm{a}} \# 1^{\mathrm{b}}$ & Dmn $\# 2^{c}$ & Dmn \#3 ${ }^{d}$ & Dmn \#4 $4^{\mathrm{e}}$ & Dmn $\# 5^{\mathrm{f}}$ & Overall risk \\
\hline Lintvedt et al, 2013 [68] & $\mathrm{SC}$ & LR & LR & $\mathrm{SC}$ & LR & $\mathrm{SC}$ \\
\hline Mailey et al, 2010 [69] & LR & LR & LR & $\mathrm{SC}$ & LR & $\mathrm{SC}$ \\
\hline Mak et al, 2015 [70] & LR & LR & LR & $\mathrm{SC}$ & LR & $\mathrm{SC}$ \\
\hline Mak et al, 2017 [71] & LR & LR & LR & LR & $\mathrm{SC}$ & $\mathrm{SC}$ \\
\hline McCall et al, 2018 [103] & LR & LR & LR & LR & LR & LR \\
\hline Melnyk et al, 2015 [72] & $\mathrm{SC}$ & LR & LR & $\mathrm{SC}$ & $\mathrm{SC}$ & HR \\
\hline Mogoaşe, 2013 [104] & LR & LR & LR & LR & LR & LR \\
\hline Morris et al, 2016 [73] & LR & LR & LR & $\mathrm{SC}$ & LR & $\mathrm{SC}$ \\
\hline Mullin et al, 2015 [74] & $\mathrm{SC}$ & LR & LR & $\mathrm{SC}$ & LR & $\mathrm{SC}$ \\
\hline Musiat et al, 2014 [75] & LR & LR & LR & LR & LR & LR \\
\hline Nguyen-Feng et al, 2015 [76] & LR & LR & LR & $\mathrm{SC}$ & LR & $\mathrm{SC}$ \\
\hline Nguyen-Feng et al, 2016 [77] & LR & LR & LR & LR & $\mathrm{SC}$ & $\mathrm{SC}$ \\
\hline Nguyen-Feng et al, 2017 [78] & LR & LR & LR & LR & LR & LR \\
\hline Nordmo et al, 2015 [79] & $\mathrm{SC}$ & LR & LR & LR & LR & $\mathrm{SC}$ \\
\hline Orbach et al, 2007 [80] & LR & LR & $\mathrm{SC}$ & LR & $\mathrm{SC}$ & $\mathrm{SC}$ \\
\hline Radhu et al, 2012 [81] & LR & LR & LR & $\mathrm{SC}$ & LR & $\mathrm{SC}$ \\
\hline Rasanen et al, 2016 [82] & LR & LR & LR & $\mathrm{SC}$ & LR & $\mathrm{SC}$ \\
\hline Richards \& Timulak, 2013 [83] & LR & $\mathrm{SC}$ & $\mathrm{SC}$ & LR & HR & HR \\
\hline Richards et al, 2013 [84] & LR & LR & LR & LR & LR & $\mathrm{LR}$ \\
\hline Richards et al, 2016 [85] & LR & LR & LR & $\mathrm{SC}$ & LR & $\mathrm{SC}$ \\
\hline Rose et al, 2013 [105] & $\mathrm{SC}$ & LR & LR & LR & LR & $\mathrm{SC}$ \\
\hline Sagon et al, 2018 [106] & $\mathrm{SC}$ & LR & LR & LR & LR & $\mathrm{SC}$ \\
\hline Saleh et al, 2018 [107] & $\mathrm{SC}$ & LR & LR & LR & LR & $\mathrm{SC}$ \\
\hline Santucci et al, 2014 [86] & LR & LR & LR & LR & LR & LR \\
\hline Sarniak, 2009 [108] & $\mathrm{SC}$ & $\mathrm{SC}$ & LR & LR & LR & $\mathrm{SC}$ \\
\hline Seligman et al, 2007 [87] & $\mathrm{SC}$ & LR & LR & $\mathrm{SC}$ & LR & $\mathrm{SC}$ \\
\hline Stallman et al, 2018 [109] & LR & LR & LR & LR & LR & LR \\
\hline Taitz, 2011 [110] & $\mathrm{SC}$ & $\mathrm{SC}$ & $\mathrm{SC}$ & LR & LR & HR \\
\hline Tillfors et al, 2008 [88] & LR & LR & LR & LR & LR & LR \\
\hline Villani \& Riva, 2008 [111] & LR & LR & LR & LR & LR & LR \\
\hline Yang et al, 2015 [89] & LR & LR & LR & $\mathrm{SC}$ & LR & $\mathrm{SC}$ \\
\hline
\end{tabular}

${ }^{\mathrm{a}}$ Dmn: domain.

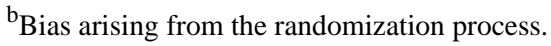

${ }^{\mathrm{c}} \mathrm{Bias}$ due to deviations from intended interventions.

${ }^{\mathrm{d}}$ Bias due to missing outcome data.

${ }^{\mathrm{e}} \mathrm{Bias}$ in measurement of the outcome.

${ }^{f}$ Bias in selection of the reported result.

${ }^{\mathrm{g}} \mathrm{LR}$ : low risk.

${ }^{\mathrm{h}} \mathrm{SC}$ : some concerns.

${ }^{\mathrm{i}} \mathrm{HR}$ : high risk. 
Table 2. Risk of bias for nonrandomized studies.

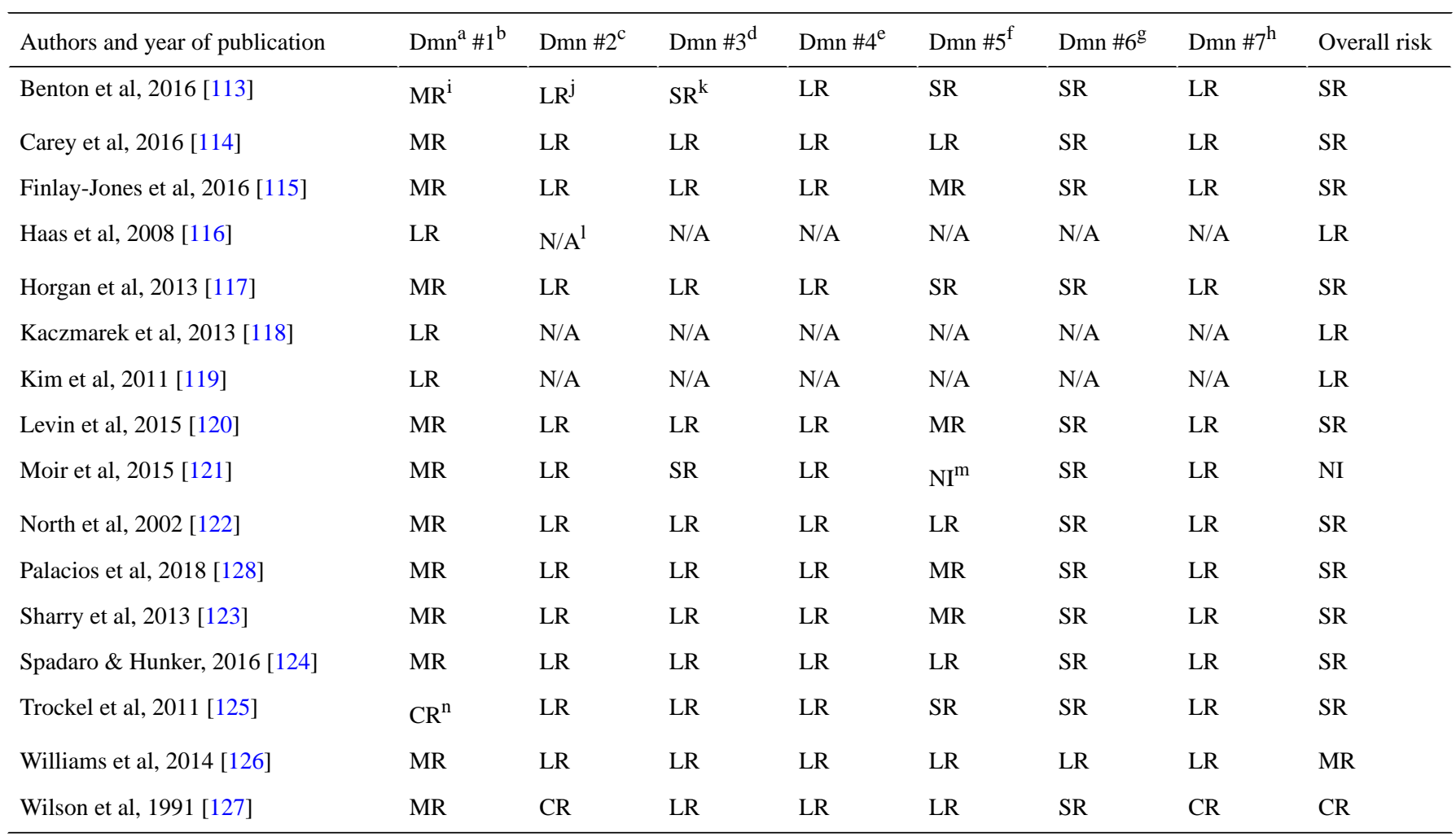

amn: domain.

${ }^{\mathrm{b}}$ Bias due to confounding.

${ }^{\mathrm{c}}$ Bias in selection of participants into the study.

${ }^{\mathrm{d}}$ Bias in classification of interventions.

${ }^{\mathrm{e}} \mathrm{Bias}$ due to deviations from intended interventions.

${ }^{\mathrm{f}}$ Bias due to missing data.

${ }^{\mathrm{g}}$ Bias in measurement of outcomes.

${ }^{\mathrm{h}}$ Bias in selection of the reported result.

${ }^{\mathrm{i}} \mathrm{MR}$ : moderate risk.

${ }^{\mathrm{j}} \mathrm{LR}$ : low risk.

${ }^{\mathrm{k} R}$ : serious risk.

${ }^{1}$ N/A: not applicable. Any study deemed low risk in Domain \#1 is considered low risk as a whole; thus, other domains are N/A.

$\mathrm{m}_{\mathrm{NI}}$ : no information.

${ }^{\mathrm{n}} \mathrm{CR}$ : critical risk.

\section{Discussion}

\section{Principal Findings}

This study aimed to synthesize the literature on the effectiveness, usability, acceptability, uptake, and adoption of digital mental health interventions for (1) treating depression and anxiety and (2) enhancing psychological well-being among college students. In doing so, the types of interventions that have been developed and tested were characterized. The vast majority of included studies reported that the digital mental health interventions of interest were either effective, or partially effective, in producing beneficial changes in the main psychological outcome variables. This is consistent with past meta-analyses on digital mental health programs for college students $[17,18]$ and is consistent with the broader literature on digital mental health interventions $[134,135]$. Effectiveness did not appear to substantially vary by type of digital mental health intervention, indicating that computer-, Web-, mobile-, and virtual reality-based interventions all hold potential for improving mental health on college campuses.

The majority of programs were studied on university campuses and enrolled broad samples of undergraduate and graduate students. The focus on universities was not surprising, as many studies were conducted at the university with which the researchers were affiliated, likely because of a combination of ease and investment in one's own community. Fewer studies took place within health professional (eg, medical school and nursing school) programs. It was notable that only 1 study comprised a community college sample, as it is widely recognized that community college students have higher rates of unmet mental health needs compared with students in traditional 4-year colleges and universities [136-138]. Furthermore, community college students are likely to face additional barriers to accessing care as they are more likely to 
attend school part-time while balancing other responsibilities and commitments, and many community college campuses do not provide mental health services [138]. Thus, this appears to be a priority area for further research and intervention development.

College students are often used as a convenience sample for psychological research [139]. Therefore, to interpret the findings in light of whether the included studies aimed to specifically target students, we examined whether the designs appeared specific to college student mental health. We found that the majority of studies $(n=68)$ were focused explicitly on college student mental health, as opposed to using students for convenience sampling. This majority finding highlights the potential for these programs to be more broadly disseminated and implemented on college campuses.

Similar to what has been observed in digital mental health intervention programs for general adult populations [22,134], there were notable rates of participant attrition and early program discontinuation in many of the studies. An individual may discontinue use of a digital mental health intervention for a variety of factors. These include positive reasons, such as early mood improvements resulting in the individual no longer having a need for the intervention tools. More often though, early discontinuation of such programs appears be the result of an unsatisfying user experience. Although user experience is multifaceted, the core components of user experiences include the program's usability and acceptability, which were a focus of this study. A recent review of user engagement with mental health apps found that problems emerge because apps (1) are not designed with users in mind, (2) do not address problems users care most about, (3) do not respect user privacy, (4) are not seen as trustworthy, and (5) are unhelpful in emergencies [140]. Although this review focused on mental health apps [140], these themes appear to be translatable to reasons for poor engagement with other types of digital mental health interventions. Indeed, these themes suggest usability problems, which decrease the likelihood of user engagement because of a mismatch of design with user needs [141,142]. The majority of interventions included in this review were unnamed programs developed for research purposes, and although many reported on participant satisfaction with the program, the extent to which the interventions were tested for user experience before these trials remains largely unknown. Utilization of user-centered design and usability testing is a growing practice in digital health interventions for depression [143], smoking cessation [144,145], and diverse patient groups [146]. Indeed, this practice promotes the likelihood that the intervention is appropriately engaging, intuitive to use, and pleasing to the intended user population. Therefore, assessing for usability is a critical component in establishing the feasibility, efficacy, and generalizability of a digital health intervention, particularly for specialty populations [147].

Although user-centered design can produce programs that are more engaging and enjoyable for users, design principles alone are unlikely to produce interventions that are sustainably used on college campuses. The research-to-practice gap for digital mental health interventions is increasingly being recognized, and leaders in the field have proposed strategies to routinely incorporate implementation science methods into the study of digital mental health interventions [148,149]. These models highlight the importance of the systems in which interventions are to be introduced, and although all studies included in this review focused on college students as a population of interest, very few examined college campus systems and tested the implementation of programs onto campuses [86,109,116,119]. Increasingly, calls are being made to collect implementation-relevant data while testing new digital mental health programs or testing existing programs on new populations [150-152]. For digital mental health to fully realize its potential for college students, digital health researchers need to embrace methods and models from implementation science, such as hybrid trial designs [153], and add to the body of knowledge on how to create and support a campus mental health system that actively uses digital mental health programs.

\section{Strengths and Limitations}

This study should be interpreted in light of its strengths and limitations. Consistent with best practices, the articles were reviewed by 2 independent reviewers and risk of bias was assessed. The moderate-to-severe risk of bias found in many of the included randomized and nonrandomized trials indicates that the results reported may be biased in favor of the digital mental health tools and should be evaluated in that context. Bias primarily emerged because the outcomes were self-reported in nature and the participants were aware of the intervention they received -2 issues that are exceedingly common in digital health research. Although the search strategy was developed with an experienced research librarian and an additional handsearch was used, it is possible that some relevant publications were missed in the search. Several reviewed studies used active controls or comparison interventions that produced similar effects to the intervention of interest, so we were unable to evaluate the effectiveness of intervention ingredients to inform what components (eg, features or techniques) are relevant for achieving behavior change. Without the gold standard interventions in digital health for college students that could serve as comparisons with newly developed interventions, several studies that were reviewed used active controls or comparison interventions that produced similar effects to the intervention of interest. In addition, none of the included studies utilized noninferiority analyses. Therefore, the true efficacy of most of the interventions was unclear.

Another strength is that we did not limit this review to RCTs of computer- and Web-based programs. As such, this study expands on past work by offering a much broader look at the types of digital mental health programs that have been available for students and a look at the uptake and adoption of such interventions. Uptake and adoption could not have been meaningfully examined if this review was limited to RCTs. However, the consequence of including multiple trial designs precluded us conducting a meta-analysis because of the heterogeneity of the data included.

\section{Conclusions}

Digital mental health interventions for depression, anxiety, and the enhancement of psychological well-being have the potential to improve the mental health of college students around the 
world. The majority of interventions have focused on Web-based technologies, and there remains a need for further research on interventions delivered via mobile phones. To date, published studies on digital mental health programs have primarily been focused on establishing efficacy and/or effectiveness rather than on supporting program uptake and adoption across campus communities. For these programs to realize their potential, they need to be successfully and sustainably implemented on college campuses as part of the array of available mental health services. Further research on digital mental health interventions for college students should focus on designing and testing programs that are viewed as usable and acceptable to students and on methods of implementing such programs on college campuses.

\section{Acknowledgments}

EGL is supported by a research grant K08 MH112878 from the National Institute of Mental Health. AKG is supported by a research grant K01 DK116925 from the National Institute of Diabetes and Digestive and Kidney Diseases.

\section{Conflicts of Interest}

None declared.

\section{Multimedia Appendix 1}

Search strategy overview.

[PDF File (Adobe PDF File), 103KB-Multimedia Appendix 1]

\section{Multimedia Appendix 2}

Study details.

[XLSX File (Microsoft Excel File), 21KB-Multimedia Appendix 2]

\section{Multimedia Appendix 3}

Study results.

\section{[XLSX File (Microsoft Excel File), 37KB-Multimedia Appendix 3]}

\section{References}

1. Pinder-Amaker S, Bell C. A bioecological systems approach for navigating the college mental health crisis. Harv Rev Psychiatry 2012;20(4):174-188. [doi: 10.3109/10673229.2012.712842] [Medline: 22894727]

2. Eisenberg D, Hunt J, Speer N. Help seeking for mental health on college campuses: review of evidence and next steps for research and practice. Harv Rev Psychiatry 2012;20(4):222-232. [doi: 10.3109/10673229.2012.712839] [Medline: 22894731]

3. Lipson SK, Lattie EG, Eisenberg D. Increased rates of mental health service utilization by US college students: 10-year population-level trends (2007-2017). Psychiatr Serv 2019 Jan 1;70(1):60-63. [doi: 10.1176/appi.ps.201800332] [Medline: 30394183]

4. Auerbach RP, Mortier P, Bruffaerts R, Alonso J, Benjet C, Cuijpers P, WHO WMH-ICS Collaborators. WHO world mental health surveys international college student project: prevalence and distribution of mental disorders. J Abnorm Psychol 2018 Oct;127(7):623-638. [doi: 10.1037/abn0000362] [Medline: 30211576]

5. Eisenberg D, Golberstein E, Gollust SE. Help-seeking and access to mental health care in a university student population. Med Care 2007 Jul;45(7):594-601. [doi: 10.1097/MLR.0b013e31803bb4c1] [Medline: 17571007]

6. Eisenberg D, Hunt J, Speer N, Zivin K. Mental health service utilization among college students in the United States. J Nerv Ment Dis 2011 May;199(5):301-308. [doi: 10.1097/NMD.0b013e3182175123] [Medline: 21543948]

7. Mowbray CT, Megivern D, Mandiberg JM, Strauss S, Stein CH, Collins K, et al. Campus mental health services: recommendations for change. Am J Orthopsychiatry 2006 Apr;76(2):226-237. [doi: 10.1037/0002-9432.76.2.226] [Medline: 16719642]

8. Xiao H, Carney DM, Youn SJ, Janis RA, Castonguay LG, Hayes JA, et al. Are we in crisis? National mental health and treatment trends in college counseling centers. Psychol Serv 2017 Nov;14(4):407-415. [doi: 10.1037/ser0000130] [Medline: 29120199]

9. Renton T, Tang H, Ennis N, Cusimano MD, Bhalerao S, Schweizer TA, et al. Web-based intervention programs for depression: a scoping review and evaluation. J Med Internet Res 2014 Sep 23;16(9):e209 [FREE Full text] [doi: 10.2196/jmir.3147] [Medline: 25249003]

10. Rai M, Vigod SN, Hensel JM. Barriers to office-based mental health care and interest in e-communication with providers: a survey study. JMIR Ment Health 2016 Aug 1;3(3):e35 [FREE Full text] [doi: 10.2196/mental.6068] [Medline: 27480108] 
11. Kass AE, Balantekin KN, Fitzsimmons-Craft EE, Jacobi C, Wilfley DE, Taylor CB. The economic case for digital interventions for eating disorders among United States college students. Int J Eat Disord 2017 Mar;50(3):250-258 [FREE Full text] [doi: 10.1002/eat.22680] [Medline: 28152203]

12. Andrews G, Cuijpers P, Craske MG, McEvoy P, Titov N. Computer therapy for the anxiety and depressive disorders is effective, acceptable and practical health care: a meta-analysis. PLoS One 2010 Oct 13;5(10):e13196 [FREE Full text] [doi: 10.1371/journal.pone.0013196] [Medline: 20967242]

13. Karyotaki E, Riper H, Twisk J, Hoogendoorn A, Kleiboer A, Mira A, et al. Efficacy of self-guided internet-based cognitive behavioral therapy in the treatment of depressive symptoms: a meta-analysis of individual participant data. JAMA Psychiatry 2017 Apr 1;74(4):351-359. [doi: 10.1001/jamapsychiatry.2017.0044] [Medline: 28241179]

14. Firth J, Torous J, Nicholas J, Carney R, Pratap A, Rosenbaum S, et al. The efficacy of smartphone-based mental health interventions for depressive symptoms: a meta-analysis of randomized controlled trials. World Psychiatry 2017 Oct;16(3):287-298 [FREE Full text] [doi: 10.1002/wps.20472] [Medline: 28941113]

15. Firth J, Torous J, Nicholas J, Carney R, Rosenbaum S, Sarris J. Can smartphone mental health interventions reduce symptoms of anxiety? A meta-analysis of randomized controlled trials. J Affect Disord 2017 Dec 15;218:15-22 [FREE Full text] [doi: 10.1016/j.jad.2017.04.046] [Medline: 28456072]

16. Farrer L, Gulliver A, Chan JK, Batterham PJ, Reynolds J, Calear A, et al. Technology-based interventions for mental health in tertiary students: systematic review. J Med Internet Res 2013 May 27;15(5):e101 [FREE Full text] [doi: 10.2196/jmir.2639] [Medline: 23711740]

17. Davies EB, Morriss R, Glazebrook C. Computer-delivered and web-based interventions to improve depression, anxiety, and psychological well-being of university students: a systematic review and meta-analysis. J Med Internet Res 2014 May 16;16(5):e130 [FREE Full text] [doi: 10.2196/jmir.3142] [Medline: 24836465]

18. Harrer M, Adam SH, Baumeister H, Cuijpers P, Karyotaki E, Auerbach RP, et al. Internet interventions for mental health in university students: a systematic review and meta-analysis. Int J Methods Psychiatr Res 2019 Jun;28(2):e1759. [doi: 10.1002/mpr.1759] [Medline: $\underline{30585363]}$

19. Glasgow RE, Phillips SM, Sanchez MA. Implementation science approaches for integrating eHealth research into practice and policy. Int J Med Inform 2014 Jul;83(7):e1-11. [doi: 10.1016/j.ijmedinf.2013.07.002] [Medline: 23910896]

20. Mohr DC, Cheung K, Schueller SM, Hendricks BC, Duan N. Continuous evaluation of evolving behavioral intervention technologies. Am J Prev Med 2013 Oct;45(4):517-523 [FREE Full text] [doi: 10.1016/j.amepre.2013.06.006] [Medline: 24050429]

21. Pham Q, Wiljer D, Cafazzo JA. Beyond the randomized controlled trial: a review of alternatives in mHealth clinical trial methods. JMIR Mhealth Uhealth 2016 Sep 9;4(3):e107 [FREE Full text] [doi: 10.2196/mhealth.5720] [Medline: 27613084]

22. Fleming T, Bavin L, Lucassen M, Stasiak K, Hopkins S, Merry S. Beyond the trial: systematic review of real-world uptake and engagement with digital self-help interventions for depression, low mood, or anxiety. J Med Internet Res 2018 Dec 6;20(6):e199 [FREE Full text] [doi: 10.2196/jmir.9275] [Medline: 29875089]

23. McCurdie T, Taneva S, Casselman M, Yeung M, McDaniel C, Ho W, et al. mHealth consumer apps: the case for user-centered design. Biomed Instrum Technol 2012;46(s2):49-56. [doi: 10.2345/0899-8205-46.s2.49] [Medline: 23039777]

24. Zapata BC, Fernández-Alemán JL, Idri A, Toval A. Empirical studies on usability of mHealth apps: a systematic literature review. J Med Syst 2015 Feb;39(2):1. [doi: 10.1007/s10916-014-0182-2] [Medline: 25600193]

25. Georgsson M, Staggers N. Quantifying usability: an evaluation of a diabetes mHealth system on effectiveness, efficiency, and satisfaction metrics with associated user characteristics. J Am Med Inform Assoc 2016 Jan;23(1):5-11 [FREE Full text] [doi: 10.1093/jamia/ocv099] [Medline: 26377990]

26. Moher D, Liberati A, Tetzlaff J, Altman DG, PRISMA Group. Preferred reporting items for systematic reviews and meta-analyses: the PRISMA statement. PLoS Med 2009 Jul 21;6(7):e1000097 [FREE Full text] [doi: 10.1371/journal.pmed.1000097] [Medline: 19621072]

27. Ouzzani M, Hammady H, Fedorowicz Z, Elmagarmid A. Rayyan-a web and mobile app for systematic reviews. Syst Rev 2016 Dec 5;5(1):210 [FREE Full text] [doi: 10.1186/s13643-016-0384-4] [Medline: 27919275]

28. Beck AT, Steer RA, Brown GK. BDI-II, Beck Depression Inventory: Manual. San Antonio, Texas: The Psychological Corporation; 1996.

29. Kroenke K, Spitzer RL, Williams JB. The PHQ-9: validity of a brief depression severity measure. J Gen Intern Med 2001 Sep;16(9):606-613 [FREE Full text] [doi: 10.1046/j.1525-1497.2001.016009606.x] [Medline: 11556941]

30. Beck AT, Epstein N, Brown G, Steer RA. An inventory for measuring clinical anxiety: psychometric properties. J Consult Clin Psychol 1988 Dec;56(6):893-897. [doi: 10.1037//0022-006X.56.6.893] [Medline: 3204199]

31. Peterson RA, Reiss S. Anxiety Sensitivity Index Manual. Worthington, Ohio: International Diagnostic Systems; 1992.

32. Cohen S, Kamarck T, Mermelstein R. A global measure of perceived stress. J Health Soc Behav 1983 Dec;24(4):385-396. [doi: 10.2307/2136404] [Medline: 6668417]

33. Ryff CD, Keyes CL. The structure of psychological well-being revisited. J Pers Soc Psychol 1995 Oct;69(4):719-727. [doi: 10.1037/0022-3514.69.4.719] [Medline: 7473027]

34. Sauro J. A Practical Guide to the System Usability Scale: Background, Benchmarks \& Best Practices. Denver, Colarado: Measuring Usability LLC; 2011. 
35. Proctor E, Silmere H, Raghavan R, Hovmand P, Aarons G, Bunger A, et al. Outcomes for implementation research: conceptual distinctions, measurement challenges, and research agenda. Adm Policy Ment Health 2011 Mar;38(2):65-76 [FREE Full text] [doi: 10.1007/s10488-010-0319-7] [Medline: 20957426]

36. Higgins JP, Sterne JA, Savović J, Page MJ, Hróbjartsson A, Boutron I, et al. A revised tool for assessing risk of bias in randomized trials. In: Chandler J, McKenzie J, Boutron I, Welch V, editors. Cochrane Methods 2016. New Jersey: Wiley; 2016:29.

37. Sterne JA, Hernán MA, Reeves BC, Savović J, Berkman ND, Viswanathan M, et al. ROBINS-I: a tool for assessing risk of bias in non-randomised studies of interventions. Br Med J 2016 Oct 12;355:i4919 [FREE Full text] [doi: 10.1136/bmj.i4919] [Medline: 27733354]

38. Snilstveit B, Oliver S, Vojtkova M. Narrative approaches to systematic review and synthesis of evidence for international development policy and practice. J Dev Econ 2012 Sep 27;4(3):409-429 [FREE Full text] [doi: $10.1080 / 19439342.2012 .710641]$

39. Siddaway AP, Wood AM, Hedges LV. How to do a systematic review: a best practice guide for conducting and reporting narrative reviews, meta-analyses, and meta-syntheses. Annu Rev Psychol 2019 Dec 4;70:747-770. [doi: 10.1146/annurev-psych-010418-102803] [Medline: 30089228]

40. Baumeister RF, Leary MR. Writing narrative literature reviews. Rev Gen Psychol 1997;1(3):311-320. [doi: 10.1037//1089-2680.1.3.311]

41. Alvarez LM, Cortés SJ, León SO, Estrella J, Sánchez SJ. Computer program in the treatment for major depression and cognitive impairment in university students. Comput Human Behav 2008 May;24(3):816-826. [doi: 10.1016/j.chb.2007.02.013]

42. Arpin-Cribbie C, Irvine J, Ritvo P. Web-based cognitive-behavioral therapy for perfectionism: a randomized controlled trial. Psychother Res 2012;22(2):194-207. [doi: 10.1080/10503307.2011.637242] [Medline: 22122217]

43. Booker JA, Dunsmore JC. Expressive writing and well-being during the transition to college: comparison of emotion-disclosing and gratitude-focused writing. J Soc Clin Psychol 2017 Sep;36(7):580-606. [doi: 10.1521/jscp.2017.36.7.580]

44. Braithwaite SR, Fincham FD. A randomized clinical trial of a computer based preventive intervention: replication and extension of ePREP. J Fam Psychol 2009 Feb;23(1):32-38. [doi: 10.1037/a0014061] [Medline: 19203157]

45. Buglione SA, DeVito AJ, Mulloy JM. Traditional group therapy and computer-administered treatment for test anxiety. Anxiety Stress Coping 1990 Jun;3(1):33-39. [doi: 10.1080/08917779008248739]

46. Chiauzzi E, Brevard J, Thum C, Thurn C, Decembrele S, Lord S. MyStudentBody-Stress: an online stress management intervention for college students. J Health Commun 2008 Sep;13(6):555-572. [doi: 10.1080/10810730802281668] [Medline: $\underline{18726812]}$

47. Cohen GE, Kerr BA. Computer-mediated counseling: an empirical study of a new mental health treatment. Comput Human Behav 1999 Apr 22;15(4):13-26. [doi: 10.1300/J407v15n04_02]

48. Cukrowicz KC, Joiner TE. Computer-based intervention for anxious and depressive symptoms in a non-clinical population. Cogn Ther Res 2007 Apr 4;31(5):677-693. [doi: 10.1007/s10608-006-9094-x]

49. Day V, McGrath PJ, Wojtowicz M. Internet-based guided self-help for university students with anxiety, depression and stress: a randomized controlled clinical trial. Behav Res Ther 2013 Jul;51(7):344-351. [doi: 10.1016/j.brat.2013.03.003] [Medline: 23639300]

50. Ellis LA, Campbell AJ, Sethi S, O'Dea BM. Comparative randomized trial of an online cognitive-behavioral therapy program and an online support group for depression and anxiety. J Cyber Ther Rehabil 2011;4(4):461-467 [FREE Full text]

51. Fernandez E, Brechtel M, Mercer A. Personal and simulated computer-aided counseling: perceived versus measured counseling outcomes for college students. J Coll Stud Dev 1986;27(3):224-228 [FREE Full text]

52. Fitzpatrick KK, Darcy A, Vierhile M. Delivering cognitive behavior therapy to young adults with symptoms of depression and anxiety using a fully automated conversational agent (WOEBOT): a randomized controlled trial. JMIR Ment Health 2017 Jun 6;4(2):e19 [FREE Full text] [doi: 10.2196/mental.7785] [Medline: 28588005]

53. Frazier P, Meredith L, Greer C, Paulsen JA, Howard K, Dietz LR, et al. Randomized controlled trial evaluating the effectiveness of a web-based stress management program among community college students. Anxiety Stress Coping 2015;28(5):576-586. [doi: 10.1080/10615806.2014.987666] [Medline: 25420030]

54. Frith E, Loprinzi P. Can Facebook reduce perceived anxiety among college students? Randomized controlled exercise trial using the transtheoretical model of behavior change. JMIR Ment Health 2017 Dec 8;4(4):e50 [FREE Full text] [doi: 10.2196/mental.8086] [Medline: 29222077]

55. Geisner IM, Varvil-Weld L, Mittmann AJ, Mallett K, Turrisi R. Brief web-based intervention for college students with comorbid risky alcohol use and depressed mood: does it work and for whom? Addict Behav 2015 Mar;42:36-43 [FREE Full text] [doi: 10.1016/j.addbeh.2014.10.030] [Medline: 25462652]

56. Grassi A, Gaggioli A, Riva G. New technologies to manage exam anxiety. Stud Health Technol Inform 2011;167:57-62. [Medline: 21685642] 
57. Guille C, Zhao Z, Krystal J, Nichols B, Brady K, Sen S. Web-based cognitive behavioral therapy intervention for the prevention of suicidal ideation in medical interns: a randomized clinical trial. JAMA Psychiatry 2015 Dec;72(12):1192-1198 [FREE Full text] [doi: 10.1001/jamapsychiatry.2015.1880] [Medline: 26535958]

58. Harris SR, Kemmerling RL, North MM. Brief virtual reality therapy for public speaking anxiety. Cyberpsychol Behav 2002 Dec;5(6):543-550. [doi: 10.1089/109493102321018187] [Medline: 12556117]

59. Hintz S, Frazier PA, Meredith L. Evaluating an online stress management intervention for college students. J Couns Psychol 2015 Apr;62(2):137-147. [doi: 10.1037/cou0000014] [Medline: 24635586]

60. Hoppitt L, Illingworth JL, MacLeod C, Hampshire A, Dunn BD, Mackintosh B. Modifying social anxiety related to a real-life stressor using online cognitive bias modification for interpretation. Behav Res Ther 2014 Jan;52:45-52 [FREE Full text] [doi: 10.1016/j.brat.2013.10.008] [Medline: 24317281]

61. Kenardy J, McCafferty K, Rosa V. Internet-delivered indicated prevention for anxiety disorders: a randomized controlled trial. Behav Cognit Psychother 2003;31(3):279-289. [doi: 10.1017/S1352465803003047]

62. King CA, Eisenberg D, Zheng K, Czyz E, Kramer A, Horwitz A, et al. Online suicide risk screening and intervention with college students: a pilot randomized controlled trial. J Consult Clin Psychol 2015 Jun;83(3):630-636 [FREE Full text] [doi: 10.1037/a0038805] [Medline: 25688811]

63. Koydemir S, Sun-Selışık ZE. Well-being on campus: testing the effectiveness of an online strengths-based intervention for first year college students. Br J Guid Counc 2015 Nov 16;44(4):434-446. [doi: 10.1080/03069885.2015.1110562]

64. Kvillemo P, Brandberg Y, Bränström R. Feasibility and outcomes of an internet-based mindfulness training program: a pilot randomized controlled trial. JMIR Ment Health 2016 Jul 22;3(3):e33 [FREE Full text] [doi: 10.2196/mental.5457] [Medline: 27450466]

65. Levin ME, Pistorello J, Seeley JR, Hayes SC. Feasibility of a prototype web-based acceptance and commitment therapy prevention program for college students. J Am Coll Health 2014;62(1):20-30 [FREE Full text] [doi: 10.1080/07448481.2013.843533] [Medline: 24313693]

66. Levin ME, Hayes SC, Pistorello J, Seeley JR. Web-based self-help for preventing mental health problems in universities: comparing acceptance and commitment training to mental health education. J Clin Psychol 2016 Mar;72(3):207-225. [doi: 10.1002/jclp.22254] [Medline: 26784010]

67. Levin ME, Haeger JA, Pierce BG, Twohig MP. Web-based acceptance and commitment therapy for mental health problems in college students: a randomized controlled trial. Behav Modif 2017 Dec 1;41(1):141-162. [doi: 10.1177/0145445516659645] [Medline: 27440189]

68. Lintvedt OK, Griffiths KM, Sørensen K, Østvik AR, Wang C, Eisemann M, et al. Evaluating the effectiveness and efficacy of unguided internet-based self-help intervention for the prevention of depression: a randomized controlled trial. Clin Psychol Psychother 2013;20(1):10-27. [doi: 10.1002/cpp.770] [Medline: 21887811]

69. Mailey EL, Wójcicki TR, Motl RW, Hu L, Strauser DR, Collins KD, et al. Internet-delivered physical activity intervention for college students with mental health disorders: a randomized pilot trial. Psychol Health Med 2010 Dec;15(6):646-659. [doi: 10.1080/13548506.2010.498894] [Medline: 21154018]

70. Mak WW, Chan AT, Cheung EY, Lin CL, Ngai KC. Enhancing web-based mindfulness training for mental health promotion with the health action process approach: randomized controlled trial. J Med Internet Res 2015 Jan 19;17(1):e8 [FREE Full text] [doi: 10.2196/jmir.3746] [Medline: 25599904]

71. Mak WW, Chio FH, Chan AT, Lui WW, Wu EK. The efficacy of internet-based mindfulness training and cognitive-behavioral training with telephone support in the enhancement of mental health among college students and young working adults: randomized controlled trial. J Med Internet Res 2017 Dec 22;19(3):e84 [FREE Full text] [doi: 10.2196/jmir.6737] [Medline: 28330831]

72. Melnyk BM, Amaya M, Szalacha LA, Hoying J, Taylor T, Bowersox K. Feasibility, acceptability, and preliminary effects of the COPE online cognitive-behavioral skill-building program on mental health outcomes and academic performance in freshmen college students: a randomized controlled pilot study. J Child Adolesc Psychiatr Nurs 2015 Aug;28(3):147-154. [doi: 10.1111/jcap.12119] [Medline: 26268362]

73. Morris J, Firkins A, Millings A, Mohr C, Redford P, Rowe A. Internet-delivered cognitive behavior therapy for anxiety and insomnia in a higher education context. Anxiety Stress Coping 2016 Dec;29(4):415-431. [doi: 10.1080/10615806.2015.1058924] [Medline: 26079158]

74. Mullin A, Dear BF, Karin E, Wootton BM, Staples LG, Johnston L, et al. The UniWellbeing course: a randomised controlled trial of a transdiagnostic internet-delivered cognitive behavioural therapy (CBT) programme for university students with symptoms of anxiety and depression. Internet Interventions 2015 May;2(2):128-136 [FREE Full text] [doi: 10.1016/j.invent.2015.02.002]

75. Musiat P, Conrod P, Treasure J, Tylee A, Williams C, Schmidt U. Targeted prevention of common mental health disorders in university students: randomised controlled trial of a transdiagnostic trait-focused web-based intervention. PLoS One 2014;9(4):e93621 [FREE Full text] [doi: 10.1371/journal.pone.0093621] [Medline: 24736388]

76. Nguyen-Feng VN, Frazier PA, Greer CS, Howard KG, Paulsen JA, Meredith L, et al. A randomized controlled trial of a web-based intervention to reduce distress among students with a history of interpersonal violence. Psychol Violence 2015;5(4):444-454. [doi: 10.1037/a0039596] 
77. Nguyen-Feng VN, Frazier PA, Greer CS, Meredith L, Howard K, Paulsen J. Testing the efficacy of three brief web-based interventions for reducing distress among interpersonal violence survivors. Transl Issues Psychol Sci 2016;2(4):439-448. [doi: $10.1037 /$ tps0000099]

78. Nguyen-Feng VN, Greer CS, Frazier P. Using online interventions to deliver college student mental health resources: evidence from randomized clinical trials. Psychol Serv 2017 Nov;14(4):481-489. [doi: 10.1037/ser0000154] [Medline: 29120206]

79. Nordmo M, Sinding AI, Carlbring P, Andersson G, Havik OE, Nordgreen T. Internet-delivered cognitive behavioural therapy with and without an initial face-to-face psychoeducation session for social anxiety disorder: a pilot randomized controlled trial. Internet Interv 2015 Nov;2(4):429-436. [doi: 10.1016/j.invent.2015.10.003]

80. Orbach G, Lindsay S, Grey S. A randomised placebo-controlled trial of a self-help internet-based intervention for test anxiety. Behav Res Ther 2007 Mar;45(3):483-496. [doi: 10.1016/j.brat.2006.04.002] [Medline: 16814744]

81. Radhu N, Daskalakis ZJ, Arpin-Cribbie CA, Irvine J, Ritvo P. Evaluating a web-based cognitive-behavioral therapy for maladaptive perfectionism in university students. J Am Coll Health 2012;60(5):357-366. [doi: 10.1080/07448481.2011.630703] [Medline: 22686358]

82. Räsänen P, Lappalainen P, Muotka J, Tolvanen A, Lappalainen R. An online guided ACT intervention for enhancing the psychological wellbeing of university students: a randomized controlled clinical trial. Behav Res Ther 2016 Mar;78:30-42. [doi: 10.1016/j.brat.2016.01.001] [Medline: 26848517]

83. Richards D, Timulak L. Satisfaction with therapist-delivered vs self-administered online cognitive behavioural treatments for depression symptoms in college students. Br J Guid Counc 2013 Apr;41(2):193-207. [doi: 10.1080/03069885.2012.726347]

84. Richards D, Timulak L, Hevey D. A comparison of two online cognitive-behavioural interventions for symptoms of depression in a student population: the role of therapist responsiveness. Couns Psychother Res 2013 Sep;13(3):184-193. [doi: 10.1080/14733145.2012.733715]

85. Richards D, Timulak L, Rashleigh C, McLoughlin O, Colla A, Joyce C, et al. Effectiveness of an internet-delivered intervention for generalized anxiety disorder in routine care: a randomised controlled trial in a student population. Internet Interv 2016 Nov;6:80-88 [FREE Full text] [doi: 10.1016/j.invent.2016.10.003] [Medline: 30135817]

86. Santucci LC, McHugh RK, Elkins RM, Schechter B, Ross MS, Landa CE, et al. Pilot implementation of computerized cognitive behavioral therapy in a university health setting. Adm Policy Ment Health 2014 Jul;41(4):514-521. [doi: 10.1007/s10488-013-0488-2] [Medline: 23592231]

87. Seligman ME, Schulman P, Tryon AM. Group prevention of depression and anxiety symptoms. Behav Res Ther 2007 Jun;45(6):1111-1126. [doi: 10.1016/j.brat.2006.09.010] [Medline: 17074301]

88. Tillfors M, Carlbring P, Furmark T, Lewenhaupt S, Spak M, Eriksson A, et al. Treating university students with social phobia and public speaking fears: internet delivered self-help with or without live group exposure sessions. Depress Anxiety 2008;25(8):708-717. [doi: 10.1002/da.20416] [Medline: 18729147]

89. Yang W, Ding Z, Dai T, Peng F, Zhang JX. Attention bias modification training in individuals with depressive symptoms: a randomized controlled trial. J Behav Ther Exp Psychiatry 2015 Dec;49(Pt A):101-111 [FREE Full text] [doi: 10.1016/j.jbtep.2014.08.005] [Medline: 25245928]

90. Asbury ET, Casey J, Desai K. Family eJournal: benefits of online guided group journaling for women. J Public Ment Health 2018 Sep 17;17(3):135-141. [doi: 10.1108/JPMH-01-2018-0008]

91. Auyeung L, Mo PK. The efficacy and mechanism of online positive psychological intervention (PPI) on improving well-being among Chinese university students: a pilot study of the best possible self (BPS) intervention. J Happiness Stud 2018 Nov 26:1-6. [doi: 10.1007/s10902-018-0054-4]

92. Bedford LA, Dietch JR, Taylor DJ, Boals A, Zayfert C. Computer-guided problem-solving treatment for depression, PTSD, and insomnia symptoms in student veterans: a pilot randomized controlled trial. Behav Ther 2018 Dec;49(5):756-767. [doi: 10.1016/j.beth.2017.11.010] [Medline: 30146142]

93. Braithwaite SR, Fincham FD. ePREP: computer based prevention of relationship dysfunction, depression and anxiety. J Soc Clin Psychol 2007 May;26(5):609-622. [doi: 10.1521/jscp.2007.26.5.609]

94. Eustis EH, Hayes-Skelton SA, Orsillo SM, Roemer L. Surviving and thriving during stress: a randomized clinical trial comparing a brief web-based therapist-assisted acceptance-based behavioral intervention versus waitlist control for college students. Behav Ther 2018 Dec;49(6):889-903. [doi: 10.1016/j.beth.2018.05.009] [Medline: 30316488]

95. Flett JA, Hayne H, Riordan BC, Thompson LM, Conner TS. Mobile mindfulness meditation: a randomised controlled trial of the effect of two popular apps on mental health. Mindfulness 2018 Oct 31;10(5):863-876. [doi: $10.1007 / \mathrm{s} 12671-018-1050-9]$

96. Freeman E, Barker C, Pistrang N. Outcome of an online mutual support group for college students with psychological problems. Cyberpsychol Behav 2008 Oct;11(5):591-593. [doi: 10.1089/cpb.2007.0133] [Medline: 18817485]

97. Fulmer R, Joerin A, Gentile B, Lakerink L, Rauws M. Using psychological artificial intelligence (Tess) to relieve symptoms of depression and anxiety: randomized controlled trial. JMIR Ment Health 2018 Dec 13;5(4):e64 [FREE Full text] [doi: 10.2196/mental.9782] [Medline: $\underline{30545815]}$ 
98. Gibbel MR. ETD Home. Bowling Green, Ohio: Bowling Green State University; 2010. Evaluating a Spiritually Integrated Intervention for Depressed College Students URL: https://etd.ohiolink.edu/!etd. send file?accession=bgsu1274920865\&disposition=inline

99. Greer C. University Digital Conservancy Home. Minnesota: University of Minnesota; 2015. An Online Mindfulness Intervention to Reduce Stress and Anxiety Among College Students URL: https://conservancy.umn.edu/bitstream/handle/ 11299/175442/Greer umn 0130E 16438.pdf?sequence=1\&isAllowed=y

100. Hall BJ, Xiong P, Guo X, Sou EK, Chou UI, Shen Z. An evaluation of a low intensity mHealth enhanced mindfulness intervention for Chinese university students: a randomized controlled trial. Psychiatry Res 2018 Dec;270:394-403. [doi: 10.1016/j.psychres.2018.09.060] [Medline: $\underline{\text { 30300870] }}$

101. Harrer M, Adam SH, Fleischmann RJ, Baumeister H, Auerbach R, Bruffaerts R, et al. Effectiveness of an internet- and app- based intervention for college students with elevated stress: randomized controlled trial. J Med Internet Res 2018 Dec 23;20(4):e136 [FREE Full text] [doi: 10.2196/jmir.9293] [Medline: 29685870]

102. Lee RA, Jung ME. Evaluation of an mHealth app (DeStressify) on university students' mental health: pilot trial. JMIR Ment Health 2018 Jan 23;5(1):e2 [FREE Full text] [doi: 10.2196/mental.8324] [Medline: 29362209]

103. McCall HC, Richardson CG, Helgadottir FD, Chen FS. Evaluating a web-based social anxiety intervention among university students: randomized controlled trial. J Med Internet Res 2018;20(3):e91 [FREE Full text] [doi: 10.2196/jmir.8630] [Medline: 29563078]

104. Mogoaşe C, Brăilean A, David D. Can concreteness training alone reduce depressive symptoms? A randomized pilot study using an internet-delivered protocol. Cognit Ther Res 2013 Jan 3;37(4):704-712. [doi: 10.1007/s 10608-012-9514-z]

105. Rose RD, Buckey JC, Zbozinek TD, Motivala SJ, Glenn DE, Cartreine JA, et al. A randomized controlled trial of a self-guided, multimedia, stress management and resilience training program. Behav Res Ther 2013 Feb;51(2):106-112. [doi: 10.1016/j.brat.2012.11.003] [Medline: 23262118]

106. Sagon AL, Danitz SB, Suvak MK, Orsillo SM. The mindful way through the semester: evaluating the feasibility of delivering an acceptance-based behavioral program online. J Contextual Behav Sci 2018 Jul;9:36-44. [doi: 10.1016/j.jcbs.2018.06.004]

107. Saleh D, Camart N, Sbeira F, Romo L. Can we learn to manage stress? A randomized controlled trial carried out on university students. PLoS One 2018;13(9):e0200997 [FREE Full text] [doi: 10.1371/journal.pone.0200997] [Medline: 30183710]

108. Sarniak RH. Carolina Digital Repository. Chapel Hill, NC: The University of North Carolina at Chapel Hill; 2009. The effects of an online intervention designed to cultivate positive emotions on emotional and health outcomes in college students URL: https://cdr.lib.unc.edu/downloads/9593tv255?locale=en

109. Stallman HM, Ohan JL, Chiera B. Reducing distress in university students: a randomised control trial of two online interventions. Aust Psychol 2018 Nov 19;54(2):125-131. [doi: 10.1111/ap.12375]

110. Taitz I. Learning lucid dreaming and its effect on depression in undergraduates. Int J Dream Res 2011;4(2):117-126. [doi: 10.11588/ijodr.2011.2.9123]

111. Villani D, Riva D. Presence and relaxation: a preliminary controlled study. PsychNol J 2008;6(1):7-25 [FREE Full text]

112. Howell AN, Rheingold AA, Uhde TW, Guille C. Web-based CBT for the prevention of anxiety symptoms among medical and health science graduate students. Cogn Behav Ther 2018 Dec 11:1-21 (forthcoming). [doi: 10.1080/16506073.2018.1533575] [Medline: 30526364]

113. Benton SA, Heesacker M, Snowden SJ, Lee G. Therapist-assisted, online (TAO) intervention for anxiety in college students: TAO outperformed treatment as usual. Prof Psychol Res Pr 2016;47(5):363-371. [doi: 10.1037/pro0000097]

114. Carey TA, Haviland J, Tai SJ, Vanags T, Mansell W. MindSurf: a pilot study to assess the usability and acceptability of a smartphone app designed to promote contentment, wellbeing, and goal achievement. BMC Psychiatry 2016 Dec 12;16(1):442

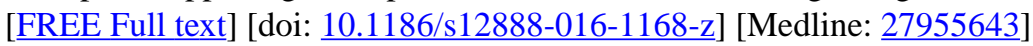

115. Finlay-Jones A, Kane R, Rees C. Self-compassion online: a pilot study of an internet-based self-compassion cultivation program for psychology trainees. J Clin Psychol 2017 Jul;73(7):797-816. [doi: 10.1002/jclp.22375] [Medline: 27787877]

116. Haas A, Koestner B, Rosenberg J, Moore D, Garlow SJ, Sedway J, et al. An interactive web-based method of outreach to college students at risk for suicide. J Am Coll Health 2008;57(1):15-22. [doi: 10.3200/JACH.57.1.15-22] [Medline: 18682341]

117. Horgan A, McCarthy G, Sweeney J. An evaluation of an online peer support forum for university students with depressive symptoms. Arch Psychiatr Nurs 2013 Apr;27(2):84-89. [doi: 10.1016/j.apnu.2012.12.005] [Medline: 23540518]

118. Kaczmarek LD, Kashdan TB, Kleiman EM, Baczkowski B, Enko J, Siebers A, et al. Who self-initiates gratitude interventions in daily life? An examination of intentions, curiosity, depressive symptoms, and life satisfaction. Pers Individ Dif 2013 Oct;55(7):805-810. [doi: 10.1016/j.paid.2013.06.013]

119. Kim EH, Coumar A, Lober WB, Kim Y. Addressing mental health epidemic among university students via web-based, self-screening, and referral system: a preliminary study. IEEE Trans Inf Technol Biomed 2011 Mar;15(2):301-307. [doi: 10.1109/TITB.2011.2107561] [Medline: 21257386]

120. Levin ME, Pistorello J, Hayes SC, Seeley JR, Levin C. Feasibility of an acceptance and commitment therapy adjunctive web-based program for counseling centers. J Couns Psychol 2015 Jul;62(3):529-536. [doi: 10.1037/cou0000083] [Medline: 25961755] 
121. Moir F, Fernando AT, Kumar S, Henning M, Moyes SA, Elley CR. Computer assisted learning for the mind (CALM): the mental health of medical students and their use of a self-help website. N Z Med J 2015 Mar 27;128(1411):51-58. [Medline: 25820503]

122. North MM, Schoeneman CM, Mathis JR. Virtual reality therapy: case study of fear of public speaking. Stud Health Technol Inform 2002;85:318-320. [doi: 10.3233/978-1-60750-929-5-318] [Medline: 15458108]

123. Sharry J, Davidson R, McLoughlin O, Doherty G. A service-based evaluation of a therapist-supported online cognitive behavioral therapy program for depression. J Med Internet Res 2013 Jun 27;15(6):e121 [FREE Full text] [doi: 10.2196/jmir.2248] [Medline: 23807565]

124. Spadaro KC, Hunker DF. Exploring the effects of an online asynchronous mindfulness meditation intervention with nursing students on stress, mood, and cognition: a descriptive study. Nurse Educ Today 2016 Apr;39:163-169. [doi: 10.1016/j.nedt.2016.02.006] [Medline: 27006051]

125. Trockel M, Manber R, Chang V, Thurston A, Taylor CB. An e-mail delivered CBT for sleep-health program for college students: effects on sleep quality and depression symptoms. J Clin Sleep Med 2011 Jun 15;7(3):276-281 [FREE Full text] [doi: 10.5664/JCSM.1072] [Medline: 21677898]

126. Williams A, Larocca R, Chang T, Trinh NH, Fava M, Kvedar J, et al. Web-based depression screening and psychiatric consultation for college students: a feasibility and acceptability study. Int J Telemed Appl 2014;2014:580786 [FREE Full text] [doi: 10.1155/2014/580786] [Medline: 24799895]

127. Wilson FR, Omeltschenko L, Yager GG. Coping with test stress: microcomputer software for treatment of test anxiety. J Behav Ther Exp Psychiatry 1991 Jun;22(2):131-139. [doi: 10.1016/0005-7916(91)90008-S] [Medline: 1684587]

128. Palacios JE, Richards D, Palmer R, Coudray C, Hofmann SG, Palmieri PA, et al. Supported internet-delivered cognitive behavioral therapy programs for depression, anxiety, and stress in university students: open, non-randomised trial of acceptability, effectiveness, and satisfaction. JMIR Ment Health 2018 Dec 14;5(4):e11467 [FREE Full text] [doi: 10.2196/11467] [Medline: $\underline{30552076}$ ]

129. Fleischmann R, Harrer M, Zarski AC, Baumeister H, Lehr D, Ebert DD. Patients' experiences in a guided internet- and app-based stress intervention for college students: a qualitative study. Internet Interv 2018 Jun;12:130-140 [FREE Full text] [doi: 10.1016/j.invent.2017.12.001] [Medline: 30135777]

130. García-Magariño I, Bedia MG, Palacios-Navarro G. FAMAP: A Framework for Developing m-Health Apps. In: Proceedings of the Trends and Advances in Information Systems and Technologies. 2018 Presented at: WorldCIST'18; March 27-29, 2018; Naples, Italy p. 850-859. [doi: 10.1007/978-3-319-77703-0 83]

131. Henriques G, Keffer S, Abrahamson C, Horst SJ. Exploring the effectiveness of a computer-based heart rate variability biofeedback program in reducing anxiety in college students. Appl Psychophysiol Biofeedback 2011 Jun;36(2):101-112. [doi: 10.1007/s10484-011-9151-4] [Medline: 21533678]

132. Brooke J. SUS-a quick and dirty usability scale. J Usability Stud 1996;189(194):4-7 [FREE Full text]

133. Attkisson CC, Zwick R. The client satisfaction questionnaire. Psychometric properties and correlations with service utilization and psychotherapy outcome. Eval Program Plann 1982;5(3):233-237. [doi: 10.1016/0149-7189(82)90074-X] [Medline: 10259963]

134. Andrews G, Basu A, Cuijpers P, Craske MG, McEvoy P, English CL, et al. Computer therapy for the anxiety and depression disorders is effective, acceptable and practical health care: an updated meta-analysis. J Anxiety Disord 2018 Dec;55:70-78 [FREE Full text] [doi: 10.1016/j.janxdis.2018.01.001] [Medline: 29422409]

135. Ebert DD, Zarski AC, Christensen H, Stikkelbroek Y, Cuijpers P, Berking M, et al. Internet and computer-based cognitive behavioral therapy for anxiety and depression in youth: a meta-analysis of randomized controlled outcome trials. PLoS One 2015;10(3):e0119895 [FREE Full text] [doi: 10.1371/journal.pone.0119895] [Medline: 25786025]

136. Fortney JC, Curran GM, Hunt JB, Cheney AM, Lu L, Valenstein M, et al. Prevalence of probable mental disorders and help-seeking behaviors among veteran and non-veteran community college students. Gen Hosp Psychiatry 2016;38:99-104 [FREE Full text] [doi: 10.1016/j.genhosppsych.2015.09.007] [Medline: 26598288]

137. Fortney JC, Curran GM, Hunt JB, Lu L, Eisenberg D, Valenstein M. Mental health treatment seeking among veteran and civilian community college students. Psychiatr Serv 2017 Aug 1;68(8):851-855. [doi: 10.1176/appi.ps.201600240] [Medline: 28412894]

138. Sontag-Padilla L, Woodbridge MW, Mendelsohn J, D'Amico EJ, Osilla KC, Jaycox LH, et al. Factors affecting mental health service utilization among California public college and university students. Psychiatr Serv 2016 Dec 1;67(8):890-897. [doi: 10.1176/appi.ps.201500307] [Medline: 27032662]

139. Hanel PH, Vione KC. Do student samples provide an accurate estimate of the general public? PLoS One 2016;11(12):e0168354 [FREE Full text] [doi: 10.1371/journal.pone.0168354] [Medline: 28002494]

140. Torous J, Nicholas J, Larsen ME, Firth J, Christensen H. Clinical review of user engagement with mental health smartphone apps: evidence, theory and improvements. Evid Based Ment Health 2018 Aug;21(3):116-119. [doi: 10.1136/eb-2018-102891] [Medline: 29871870]

141. Chiu TM, Eysenbach G. Stages of use: consideration, initiation, utilization, and outcomes of an internet-mediated intervention. BMC Med Inform Decis Mak 2010 Nov 23;10:73 [FREE Full text] [doi: 10.1186/1472-6947-10-73] [Medline: 21092275] 
142. Price M, Yuen EK, Goetter EM, Herbert JD, Forman EM, Acierno R, et al. mHealth: a mechanism to deliver more accessible, more effective mental health care. Clin Psychol Psychother 2014;21(5):427-436 [FREE Full text] [doi: 10.1002/cpp.1855] [Medline: 23918764]

143. Stiles-Shields C, Montague E, Lattie EG, Schueller SM, Kwasny MJ, Mohr DC. Exploring user learnability and learning performance in an app for depression: usability study. JMIR Hum Factors 2017 Aug 11;4(3):e18 [FREE Full text] [doi: 10.2196/humanfactors.7951] [Medline: 28801301]

144. Vilardaga R, Rizo J, Kientz JA, McDonell MG, Ries RK, Sobel K. User experience evaluation of a smoking cessation app in people with serious mental illness. Nicotine Tob Res 2016 May;18(5):1032-1038 [FREE Full text] [doi: 10.1093/ntr/ntv256] [Medline: 26581430]

145. Vilardaga R, Rizo J, Zeng E, Kientz JA, Ries R, Otis C, et al. User-centered design of learn to quit, a smoking cessation smartphone app for people with serious mental illness. JMIR Serious Games 2018 Jan 16;6(1):e2 [FREE Full text] [doi: 10.2196/games.8881] [Medline: 29339346]

146. Sarkar U, Gourley GI, Lyles CR, Tieu L, Clarity C, Newmark L, et al. Usability of commercially available mobile applications for diverse patients. J Gen Intern Med 2016 Dec;31(12):1417-1426 [FREE Full text] [doi: 10.1007/s11606-016-3771-6] [Medline: 27418347]

147. Stiles-Shields C, Holmbeck GN. JPP student journal club commentary: smartphone-delivered interventions for pediatric populations: improving methodologies to address concerns of feasibility and efficacy. J Pediatr Psychol 2018 Jun 1;43(5):485-487 [FREE Full text] [doi: 10.1093/jpepsy/jsy018] [Medline: 29546284]

148. Lattie EG, Ho J, Sargent E, Tomasino KN, Smith JD, Brown CH, et al. Teens engaged in collaborative health: the feasibility and acceptability of an online skill-building intervention for adolescents at risk for depression. Internet Interv 2017 Jun;8:15-26 [FREE Full text] [doi: 10.1016/j.invent.2017.02.003] [Medline: 28584734]

149. Greenhalgh T, Wherton J, Papoutsi C, Lynch J, Hughes G, A'Court C, et al. Beyond adoption: a new framework for theorizing and evaluating nonadoption, abandonment, and challenges to the scale-up, spread, and sustainability of health and care technologies. J Med Internet Res 2017 Dec 1;19(11):e367 [FREE Full text] [doi: 10.2196/jmir.8775] [Medline: 29092808]

150. Wozney L, McGrath PJ, Gehring ND, Bennett K, Huguet A, Hartling L, et al. eMental healthcare technologies for anxiety and depression in childhood and adolescence: systematic review of studies reporting implementation outcomes. JMIR Ment Health 2018 Jun 26;5(2):e48 [FREE Full text] [doi: 10.2196/mental.9655] [Medline: 29945858]

151. Vis C, Mol M, Kleiboer A, Bührmann L, Finch T, Smit J, et al. Improving implementation of eMental health for mood disorders in routine practice: systematic review of barriers and facilitating factors. JMIR Ment Health 2018 Mar 16;5(1):e20 [FREE Full text] [doi: 10.2196/mental.9769] [Medline: 29549072]

152. Hill C, Creswell C, Vigerland S, Nauta MH, March S, Donovan C, et al. Navigating the development and dissemination of internet cognitive behavioral therapy (iCBT) for anxiety disorders in children and young people: a consensus statement with recommendations from the \#iCBTLorentz Workshop Group. Internet Interv 2018 Jun;12:1-10 [FREE Full text] [doi: 10.1016/j.invent.2018.02.002] [Medline: 30135763]

153. Curran GM, Bauer M, Mittman B, Pyne JM, Stetler C. Effectiveness-implementation hybrid designs: combining elements of clinical effectiveness and implementation research to enhance public health impact. Med Care 2012 Mar;50(3):217-226 [FREE Full text] [doi: 10.1097/MLR.0b013e3182408812] [Medline: 22310560]

\section{Abbreviations \\ PRISMA: Preferred Reporting Items for Systematic Reviews and Meta-Analyses \\ RCT: randomized controlled trial}

Edited by G Eysenbach; submitted 20.11.18; peer-reviewed by E Montague, K Mishina, N Gehring, EB Davies, A Newton; comments
to author 17.04.19; revised version received 29.05.19; accepted 14.06.19; published 22.07.19
Please cite as:
Lattie EG, Adkins EC, Winquist N, Stiles-Shields C, Wafford QE, Graham AK
Digital Mental Health Interventions for Depression, Anxiety, and Enhancement of Psychological Well-Being Among College Students:
Systematic Review
J Med Internet Res 2019;21(7):e12869
URL: $\underline{\text { http://www.jmir.org/2019/7/e12869/ }}$
doi: $\underline{10.2196 / 12869}$
PMID: $\underline{31333198}$

(CEmily G Lattie, Elizabeth C Adkins, Nathan Winquist, Colleen Stiles-Shields, Q Eileen Wafford, Andrea K Graham. Originally published in the Journal of Medical Internet Research (http://www.jmir.org), 22.07.2019. This is an open-access article distributed 
under the terms of the Creative Commons Attribution License (https://creativecommons.org/licenses/by/4.0/), which permits unrestricted use, distribution, and reproduction in any medium, provided the original work, first published in the Journal of Medical Internet Research, is properly cited. The complete bibliographic information, a link to the original publication on http://www.jmir.org/, as well as this copyright and license information must be included. 